\title{
The Research on the Impact of Covid-19 on U.S. Resource Stock Market
}

\author{
Jiatong Sun ${ }^{1, *}$, , Bijia Yang ${ }^{2, \dagger}$, Dongping $\mathrm{Yu}^{3, \dagger}$, Lingfeng Zhang ${ }^{4, \dagger}$ \\ ${ }^{1}$ King's Business School, King's College London, London WC2R 2LS, United Kingdom \\ ${ }^{2}$ Faculty of Natural, Mathematical \& Engineering Sciences, King's College London, WC2R 2LS, United Kingdom \\ ${ }^{3}$ Institute of economics, Sichuan Agricultural University, Chengdu 611130, China \\ ${ }^{4}$ Big data management and Application, Beijing Information Science and Technology University, Beijing 100096, \\ China \\ *Corresponding author. Email: K19051365@kcl.ac.uk \\ These authors contributed equally.
}

\begin{abstract}
2020 is a challenging year for humans because the whole world was under attack of COVID-19, which is considered the most transmissible virus throughout human history. This pandemic has caused an unprecedented negative impact on people's lives and the world's economy. In addition, the impact of the pandemic on the stock market is nonnegligible, as well. This article is mainly centered on the impact of COVID-19 on the stock market of four specific resource industries, which are Coal, Oil, Mines, and Gold, by using mathematical models. The models include the CAPM model, Fama-French Three-factor model, and Fama-French Five-factor model. To obtain the impact of the COVID-19, by using the data of the expected return $\left(\mathrm{R}_{\mathrm{i}}\right)$ of the industries, a regression analysis is performed on each factor of the FamaFrench Five-factor model and the expected return of the stock market of the four industries before and after the epidemic, and obtain the impact of the epidemic on the stock market of the industry by observing the performance of the factors. The results of the multiple linear regression indicate that the epidemic has the greatest impact on the stock market of the gold industry because the four factors of the gold industry have undergone significant changes before and after the epidemic. For the Coal and the Oil industry, only the factor of HML can present the impact of the epidemic. COVID19 contributes the least impact for the mines industry because whether the factors are significant does not change.
\end{abstract}

Keywords: COVID-19, CAPM Model, Fama-French Five-factor Model

\section{INTRODUCTION}

\subsection{Background}

Everyone has already been left with an indelible impression with the COVID-19 sweeping across the globe. It had a huge crush on every aspect of humans' life, such as the tourism and catering industries, and the way people live has been influenced dramatically. When considering the situation in the US, the disease has caused a recession in the economy, particularly in the capital market. This is also the case when it comes to the resource industry. In terms of coal, oil, mines, and gold, the degree of the pandemic's impact on these industries varies, and their behavior in response to the epidemic showed different results, respectively. As the demand for these resources expanded in general, their production and transportation process has been suspended with no projected duration.

Capital Asset Pricing Model (CAPM) mainly focuses on the relationship between the expected rate of return of assets and market risk in the securities market and how the equilibrium price is formed. It is the pillar of modern financial market price theory and is widely used in the field of investment decision-making and corporate finance. In terms of asset valuation, the capital asset pricing model is mainly used to judge whether the market misprices securities. An important application of the capital asset pricing model in resource allocation is to select different assets according to the prediction of market trend $\beta$ Coefficient of securities or portfolios to obtain higher returns or avoid market risks. Innumerous fluctuations on the Stock Exchange have been reckoned to be irrational for the duration of COVID-19. Since the 
economy is vital to the operation and management of a country, it is necessary to study how the stock market became so and what measures are to be taken to recover the whole economy to the most extent.

\subsection{Related research}

The continuous outbreak of the epidemic has promoted the irrational rise and fall of financial asset prices. To figure out the impact of COVID-19 on the U.S stock market, Lee studied the correlation between the COVID-19 sentiment and 11 select sector indices. Firstly, Lee set up a terminology called Daily News Sentiment Index (DNSI), representing the extent of positive/negative sentiment, to find the distribution of the select sector indices and DNSI for the period before and after the COVID-19. Secondly, Lee also found the correlation by using the Hypothesis test and time regression model. At last, Lee concluded that in the sample distribution, the average DNSI before the pandemic is higher than that after the pandemic, and there is a positive correlation between the stock industry and the DNSI, which means the public mood can positively affect the public's investment behavior in all the industries [1]. Mazur et al. investigated how the stock market performed during the pandemic in March 2020. The study is performed using the method of statistics from the database of 1500 firms of S\&P. To derive the data, the data was matched by ticker with CRSP Daily Stock File and Compustat Index Constituents. Finally, the result indicated that during the COVID-19 period in March 2020, the stock prices of some industries such as crude petroleum, real estate, entertainment, and hospitality sectors decreased drastically. Whereas, the stock prices of some sectors such as food, health care, and software experienced a rise [2]. Baker et al. found that the previous infectious virus outbreak had little contribution to the extraordinary volatility of the stock market. By contrast, COVID-19 impacted the equity market severely. To verify this fact, statistics models called newspaper-based Equity Market Volatility (EMV) and VIX were used by Baker, Bloom, Davis, et al. This method aims to calculate out the fraction of articles that include the stock market volatility among 11 leading U.S newspapers. The outcome shows that the EMV value reached a peak in 2020 during the pandemic, although a more severe pandemic called Spanish flu happened in previous times. This concludes that the huge volatility does not attribute to the high lethal rate but the government's response policy and commercial restrictions [3]. COVID-19 has reverberated across economies and financial markets. It has severely impacted the global economy and financial markets. Policies such as workplace closures or restrictions on residents' movement have helped curb the spread of the infection while also having a huge impact on the economy. This paper reacts to the impact of the outbreak on financial markets by examining stock volatility. The measures taken by governments in response to the epidemic may have two effects on volatility. On the one hand, changes in future economic conditions may affect changes in cash flow expectations affecting companies and thus stock prices. On the other hand, a deterioration in the economic environment may cause people to flee to safety, leading to rapid portfolio movements and price changes. At the same time, the widespread cancellation of public events is a major factor contributing to increased volatility [4]. Liu et al. seeks to explore the direct and spillover effects of COVID-19 on stock markets. On the one hand, two conclusions are drawn that COVID-19 has a negative but short-term impact on the stock markets of the affected countries, and on the other hand, that the impact of COVID-19 on stock markets has a two-way spillover effect between Asian countries and European and American countries. However, there is no evidence that the negative impact of COVID-19 on the stock markets of these countries was greater than the impact on the global average. During the epidemic, China's small and medium-sized enterprises, which have been severely affected by the decline in social consumption and rigid expenditure on rents, wages, and interest, may also affect the stability of banks. This Black Swan event will cause fear among international investors and lead to a sharp panic selling reaction that will seriously affect normal life [5]. Sulistiowatietal tended to analyze the risk data of Aneka Tambang gold price and Aneka Tambang closing price, with the help of an estimated Shortfall, which is usually used to measure the risk of investing in stocks. To find out the cause of reverse tendency, where Aneka Tambang gold price rose, following the rise of world gold price. At the same time, stock investment declined, quantitative research method has been adopted, and Autoregressive conditional heteroskedasticity model has been used when computing the estimated Shortfall. The conclusion suggested that Antam stock price was well over the estimated Shortfall value of Antam gold price [6]. Gao et al. presented a novel way to compare the impact of coronavirus on stock market volatility between the U.S. and China. The quantitative method is applied when comparing the different situations where the coronavirus has been reasonably controlled. In the U.S., there is still an increasing amount of new daily cases, which made the U.S. stock insensitive to coronavirus. In addition, the particularly loose interest rate policy also suppressed the volatility of the U.S. stock market. In conclusion, before the coronavirus has been efficiently taken under control, the financial market can differently respond to different epidemic management, and the most suitable solution tends to stabilize the market [7].

In response to the fact that COVID-19 had to suspend the business of the restaurant facilities, the economy was affected. Arun and Ozili analyzed the impact of the COVID-19 outbreak on financial markets. The COVID19 has isolated people in their homes and kept them at a 
social distance. As a result, the global economy has been significantly negatively affected, for example, by the suspension of airlines to the tune of US\$113 billion, the closure of restaurants around the world, and the postponement of sporting events such as the Tokyo Olympics and the World Snooker Championship. In addition, travel restrictions imposed during the outbreak led to a reduction in the movement of people and goods, resulting in lower demand for aviation fuel, coal, and other energy products and subsequently lower oil prices due to low demand. The COVID-19, which has halted teaching at universities and colleges around the world, has cost the higher education industry up to US\$600 billion. On the other hand, the virus is a warning to health organizations around the world. Improve public health care systems and improve basic medical facilities and emergency response programs [8]. The outbreak of the Coronavirus (COVID-19) that has begun in December 2019 drastically affected the world. Endemic Coronavirus (COVID-19) is rapidly growing across the globe. SARS-CoV-2 is the virus name that causes a highly contagious and deadly disease, COVID-19. It also entered India by the end of January 2020 and has significantly influenced India. More than two million people worldwide have been confirmed to have been contaminated with this virus as of the date (29 July 2020), and more than 724,000 have died of this disease. The governments of most countries, including India, have already taken several measures to reduce the spread of COVID-19, such as lockdown, social distancing, closure of shopping malls, gyms, schools, universities, religious gatherings, etc. This lockdown has affected every Indian sector, such as the Economy, Retail Sector, Tourism Industry, etc. This paper aims to explore the extent to which a 2020 epidemic like COVID-19 impacted the Indian economy using a machine learning approach. The statistical data from esteemed and trustworthy information sources were gathered to realize the impact of the Corona Virus on the Indian economy. Based on this trusted data, analysis has been performed using the various regression models [9].

When China's economy is affected by the epidemic, and the government encourages consumption while restoring the economy. Under the impact of the epidemic and policy responses, China's economy in 2020 is expected to maintain a "low rebound and overall soundness". However, as a major public health event, the long-term impact of COVID-19 on China's economy should not be ignored. Based on confirming preventive savings at the micro level, this paper uses the macro neoclassical economic growth model to point out that the COVID-19 epidemic may promote China's savings rate to increase the potential output level in the medium and long term. However, given the continued downturn in the global economy, a rebound in China's savings rate may exacerbate the global economic imbalance. Therefore, the Chinese government needs to make a good plan to strengthen international cooperation while actively encouraging consumption to stimulate domestic demand [10]. As the world's most potential consumer market, China's new consumer economy, which consists of new demand, new supply, new fields, and new technologies, is full of vitality. In recent years, influenced by the economic and social development, the constantly updated consumption concept, and with the rapid development of technology in the Internet field, the new consumption economy such as health care, education, entertainment, and tourism are changing with each passing day. In addition, under the influence of COVID19, "Contactless delivery" continues to be popular in online shopping, takeaway, and online consultation. Combined with the impact of the epidemic, this paper makes an in-depth analysis of the development of China's new consumer economy, as well as the opportunities and challenges [11].

The United States saves the economy through industry and controlling the epidemic. Thorbecke reviewed the impact of the coronavirus crisis on the economic environment and tried to figure out the main solution to recover the U.S. economy. The return rate of 125 elective stocks in different industries has been chosen to represent its specific impact. The return has been divided into departmental and macroeconomic factors, respectively. After the quantitative research method is adopted to engage in deeper thinking of what measures to take regarding different industries, the conclusion implies that some fields such as tourism and real estate do not depend on the macroeconomic environment. However, on the control on the epidemic, whereas the others, where production equipment and electrical and electronic devices are necessary, need allround improvement including macroeconomic revival instead of a single aspect adjustment [12].

\section{METHOD}

\subsection{CAPM model}

For CAPM model, which describes the relationship between the market risk and the expected return for stocks. the equation for this model is presented as

$$
E\left(R_{i}\right)=R_{f}+\beta_{1}\left[E\left(R_{m}\right)-R_{f}\right]
$$

Where $E\left(R_{i}\right)$ represents the expected return of a particularly risky asset, particularly stocks, $\mathrm{Rf}$ means the risk-free rate, which takes the time value of money into the account. For $E\left(R_{m}\right)-R_{f}$, this factor represents the market's expected return above the risk-free rate. It is also called the market risk premium. $\beta_{1}$ is the measure of how risky the stock is compared with the market. As a whole, the CAPM model accounts for the time value of money $\left(R_{f}\right)$ and the risk $\left(\beta_{1}\right)$ to calculate the expected return of the asset. 


\subsection{Fama-French Three-factor model}

However, it is not totally rational to price the stock by only using CAPM. The reason is that the return of the stock is not merely dependent on the market. Thus, in 1992, a more advanced model compared with CAPM is founded by Fama and French, which is called FamaFrench 3-factor model. The equation is described as

$$
E(R i)-R_{f}=\beta_{1}\left[E\left(R_{m}\right)-R_{f}\right]+\beta_{2} S M B+\beta_{3} H M L(2)
$$

This model introduces two additional factors, which are SMB and HML, and their corresponding factor coefficients $\beta_{2}$ and $\beta_{3}$. The factor SMB is named as the size premium. It represents that the weighted average return generated by smaller market capitalization companies minus the weighted average return of larger market capitalization companies. The other factor called HML means that the excess return that value stock has a higher book value/market value ratio versus growth stock which has a lower ratio.

\subsection{Fama-French Five-factor model}

As a more advanced model than the 3-factor model, the Fama-French Five-factor model provides a more comprehensive explanation for the asset return. As it is described as

$$
\begin{gathered}
E\left(R_{i}\right)-R_{f}=\beta_{1}\left[E\left(R_{m}\right)-R_{f}\right]+\beta_{2} S M B+\beta_{3} H M L+ \\
\beta_{4} R M W+\beta_{5} C M A
\end{gathered}
$$

This model takes the factor of profitability and investment attitude into consideration. RMW means the average return of investing on companies with high profitability minus the average return of investing on low-profit companies. CMA means the difference between the average return generated by conservative investment and the average return generated by the aggressive investment.

\section{RESULTS}

This paragraph focuses on how the COVID-19 pandemic influenced the resource industries. It is divided into two parts, and these two attached tables show the situation before (May 2019 to February 2020) and after (March 2020 to December 2020) the pandemic. Using the Multifactor Regression Model, namely the five-factor asset pricing model, the t-statistic, P-value, and the interval in terms of the indicators in coal, oil, mines, and golds can be demonstrated. The results are obtained in Tables 1.2.3 and 4.

Table 1. Relevant values of the coal industry

\begin{tabular}{lllll}
\hline & Period & Coefficient & t-stat & P-value \\
\hline Mkt-Rf & Before & 0.85 & 5.64 & 0.00 \\
& After & 1.02 & 9.68 & 0.00 \\
\hline
\end{tabular}

\begin{tabular}{lllll}
\hline SMB & Before & 1.77 & 6.28 & 0.00 \\
& After & 0.56 & 2.1 & 0.04 \\
HML & Before & 0.33 & 1.14 & 0.26 \\
& After & 0.73 & 3.32 & 0.00 \\
RMW & Before & 0.78 & 1.64 & 0.10 \\
& After & -0.19 & -0.43 & 0.67 \\
& Before & 0.02 & 0.03 & 0.98 \\
& After & 0.85 & 1.48 & 0.14 \\
\hline
\end{tabular}

Table 2. Relevant values of the oil industry

\begin{tabular}{lllll}
\hline & Period & Coefficient & t-stat & P-value \\
\hline Mkt-Rf & Before & 0.68 & 9.91 & 0.00 \\
& After & 0.75 & 19.26 & 0.00 \\
SMB & Before & 0.53 & 4.09 & 0.00 \\
& After & 0.74 & 7.34 & 0.00 \\
HML & Before & 0.05 & 0.39 & 0.70 \\
& After & 0.20 & 2.44 & 0.02 \\
& Before & 0.23 & 1.07 & 0.29 \\
RMW & After & -0.11 & -0.63 & 0.53 \\
& Before & 0.20 & 0.78 & 0.44 \\
CMA & After & 0.10 & 0.47 & 0.64 \\
\hline & & &
\end{tabular}

Table 3. Relevant values of mines industry

\begin{tabular}{lllll}
\hline & Period & Coefficient & t-stat & P-value \\
\hline Mkt-Rf & Before & 1.02 & 10.24 & 0.00 \\
& After & 1.05 & 16.11 & 0.00 \\
SMB & Before & 1.04 & 5.58 & 0.00 \\
& After & 0.96 & 5.75 & 0.00 \\
HML & Before & 0.48 & 2.48 & 0.01 \\
& After & 0.58 & 4.25 & 0.00 \\
RMW & Before & 0.65 & 2.07 & 0.04 \\
& After & -0.57 & -2.06 & 0.04 \\
& Before & 0.71 & 1.91 & 0.06 \\
CMA & After & 0.20 & 0.57 & 0.57
\end{tabular}

Table 4. Relevant values of the gold industry

\begin{tabular}{lllll}
\hline & Period & Coefficient & t-stat & P-value \\
\hline Mkt-Rf & Before & 0.09 & 0.43 & 0.67 \\
& After & 0.90 & 8.07 & 0.00 \\
SMB & Before & 0.00 & -0.01 & 0.99 \\
& After & 1.01 & 3.50 & 0.00 \\
\hline
\end{tabular}




\begin{tabular}{lllll}
\hline HML & Before & 0.29 & 0.70 & 0.49 \\
& After & 0.69 & 2.91 & 0.00 \\
RMW & Before & -1.38 & -2.02 & 0.04 \\
& After & -0.73 & -1.52 & 0.13 \\
CMA & Before & 1.49 & 1.84 & 0.07 \\
& After & 0.73 & 1.59 & 0.11 \\
\hline
\end{tabular}

As shown in the Tables above, before the onset of the COVID-19, the HML, RMW, and CMA for coal and oil are all non-significant as they compared to t-values of less than 1.96. For gold, all five factors are nonsignificant. For p-values, CMA greater than 0.05 is significant for all four product types, and values of 0.70 and 0.49 for HML for oil and gold, respectively, are both greater than 0.05 and also significant. When the COVID19 arrived, it was clear that the values of the five factors for all four products changed significantly. Specifically, the values for coal, oil, and mine Mkt-Rf, SMB, and HML are all greater than 1.96, which are clearly significant. In terms of $p$-values, most of the p-values Mkt-RF, SMB, and HML for the three products of coal, oil, and mines were less than 0.05 and are not significant. For gold, most of the p-values before and after the epidemic changed from significant to non-significant.

\section{DISCUSSION}

\subsection{Coal}

The main idea of the discussion is centered on the tstatistics and the coefficients of each factor of the FamaFrench Five-factor model to infer that if each factor significantly influences the expected return of investing in the coal industry. First, from the multiple linear regression table above, it indicates that before the pandemic, coefficients of Mkt-Rf and SMB are statistically significantly different from 0 by looking at the t-statistics of these two factors, which means that these two factors have certain contributions to the volatility of the stock market of the coal industry. After the pandemic, three factors are becoming significant. They are Mkt-Rf, SMB, and HML. Therefore, HML is most affected by the epidemic. Second, because the coefficients of Mkt-Rf, SMB, and HML are positive, which are 0.85 (Mkt-Rf) and $1.77(\mathrm{SMB})$ before the epidemic and 1.02(Mkt-Rf), 0.56(SMB), and 0.73(HML) after the epidemic, it can be inferred that no matter the epidemic happened or not, the return on the value-weight market portfolio before the COVID-19 is greater than the risk-free return, the weighted average return of investing in companies with small market value is more than that of investing in companies with big market value, and the average return of value stock is more than that of growth stocks. Another important point is that HML is not significant before COVID-19 but significant after the epidemic. The reason for this reversion is that people's attitude to investment in the coal industry has changed before and after the pandemic. Before the epidemic, the investors' preference towards investing value stock or growth stock is not obvious. This is why the HML factor is not significant before the pandemic. However, after the pandemic, investors prefer the value stock more than the growth stock because companies with value stocks are stable. COVID-19 has marginally hit the coal industry, whereas some industries, such as the entertainment and petrol industries, have been severely hit. As the heating system and cooking are operational no matter whether coronavirus exists or not, the demand and supply of coal did not decrease severely, and coal industries maintain profitability and stability. Compared with industries with potential growth, which may be simultaneously negatively affected by the pandemic due to its high volatility, coal industries with value stock is stable before or after the COVID-19's attack. With the preference of investors changing after the pandemic, HML became significant.

\subsection{Oil}

The impact is captured by analyzing the t-values corresponding to the Fama-French Five-factor in Table 2. It is found that before the epidemic, only Mkt-Rf and SMB are significant, and both are greater than 0 . This means that the return on the value-weight market portfolio before the COVID-19 is greater than the riskfree return, indicating that the monthly return is higher than the risk-free return. The return of a diversified portfolio of small stocks is also greater than a diversified portfolio of big stocks, suggesting that smaller companies are returning better than larger ones. After the onset of the epidemic, it is clear to see that HML has gone from insignificant to significant, indicating that the return on high $\mathrm{B} / \mathrm{P}$ company stocks is greater than the return on low $\mathrm{B} / \mathrm{P}$ company stocks. These changes may be because the COVID-19 has caused people to isolate themselves at home and keep social distance, and the global economy has been severely negatively affected. As a result, for example, travel restrictions imposed during the outbreak have led to a reduction in the movement of people and goods, resulting in a reduction in demand for aviation fuel, oil, and other energy products, and subsequently a reduction in oil prices due to lower demand. As a result, value stocks had higher returns than growth stocks.

\subsection{Mines}

These data were analyzed before and after COVID19. Table 3 reveals that before the epidemic, by using the Fama-French Five-factor model, only the coefficients of Mkt-Rf, SMB, HML, and RMW are far greater than 0, and only CMA is far less than 0. According to P-value, Mkt-Rf, SMB, HML, and RMW are all less than 0.05. The model is significant, which reflects the overall regression. After the outbreak, Mkt-Rf and HML 
increased significantly, which shows that the return of high $\mathrm{B} / \mathrm{P}$ company stock is greater than that of low $\mathrm{B} / \mathrm{P}$ company stock. The reason for this may be the closure measures taken by COVID-19. Most of the mining industries are closed, people's demand becomes smaller, and the supply of mine owners will be less. For example, to actively respond to the proposal of epidemic prevention, workers need to maintain a certain safety distance, which greatly reduces the work efficiency. Therefore, the return of value stocks is higher than that of growth stocks. The slow progress of the mining industry has led to the lack of production of raw materials and led to chip manufacturing failing to meet the expected orders, thus affecting cars, the internet, and so on. After the epidemic outbreak, large companies may be able to carry it, and the difficulties faced by small and medium-sized companies are more serious. First, control towards traffic led to a significant increase in product transportation costs. Second, cash flow was challenged. Third, the risk of order default increases, and subsequent order transactions are affected. Fourth, the import and export business is affected by Entry-Exit control.

\subsection{Gold}

In this paragraph, the main focus is on the gold section, and before coming to a conclusion on how the COVID-19 has affected its investors' decisions, analyzing the outcome from those data is what comes in the first place. When using the Fama-French Five-factor model, it needs to be determined which factors are statistically significantly different from zero in the first step, and this can be achieved by considering the tStatistics value. As shown in Table 4, it can be observed that before the COVID-19, only the difference between the returns on diversified portfolios of stocks with robust and weak profitability (RMW) is valid, whereas, after the COVID-19, the factors include three: the return on the value-weight market portfolio minus the risk-free rate return (Mkt-Rf), the return on a diversified portfolio of small stocks minus the return on a diversified portfolio of big stocks(SMB), and the difference between the returns on diversified portfolios of high and low $\mathrm{B} / \mathrm{M}$ stocks(HML). A more detailed look at the table reveals that the coefficients of these factors are $-1.38(\mathrm{RMW})$, 0.9(Mkt-Rf), 1.01(SMB), and -0.69(HML), which indicate that before the COVID-19, the return on the weak operating profitability portfolios is higher than the robust ones. In contrast, after the COVID-19, the return on the value-weight market portfolio is higher than the risk- free rate return, the return on the small stock portfolios is higher than the big ones. The return on the growth portfolios is higher than the value ones. It can be inferred that these largely result from the COVID-19. Unlike the other resources that have been referred to earlier, gold is also a form of currency and is of the highest value. Considering its unique double roles, gold plays an increasingly vital part in people avoiding risks.
As is well-known, usually when the macroeconomy faces a downturn, the gold price goes up, owing to its expanding demand. Before it happened, the investors searched for instability, which signifies high risk, and we know that high risk brings high returns. After this epidemic, the investors retreat their money and search for gold and other steady values. Since those big and value stock portfolios have lost their investment capital which the government used to regenerate revenue, the money now is mostly put into medical cure and research departments instead. In addition, the small stock portfolios are easier to lift with the same amount of investment expenditure, as well as the growth portfolios have more accessibilities to initiate innovations and reformation, which are much more flexible when confronted with such financial difficulties, and that is the reason why the remain has been put into the small and growth stock portfolios, which can bring hope and even turning point thus more possibilities to evoke the capital market.

The epidemic has the greatest impact on the gold industry because the significance of four out of five factors has changed after the epidemic. The epidemic had the least impact on the Mines industry because the significance of all five factors before or after the epidemic has remained the same. For both the Coal and Oil industries, the pandemic has impacted the significance of HML. For the Coal, Oil, and Mines industries, the coefficients of factor RMW have changed from positive to negative, whereas for Gold, factor CMA has changed from positive to negative.

\section{CONCLUSION}

This article first gave a brief introduction to the arrival of the COVID-19 and described how this pandemic put pressure on every aspect of human lives, including the impact on the stock market when concerning the world economy. This was followed by previous studies and research of some related main themes, which gave this article some possibilities and direction. This article mainly focused on the impact that the COVID-19 had on four industries, including Coal, Oil, Mines, and Gold, and discussed how their stock reacted, respectively. The CAPM and the Fama-French model are referred to as the approach of this article. After that, regression is used when conducting the data analysis phase. The results suggest that the Gold industry was influenced largely, whereas the pandemic little influenced the Mines industry. This guides people on the investment decisions relating to these industries on the background of the Black Swan incidents.

\section{REFERENCES}

[1] Baker, S. R., Bloom, N., Davis, S. J., Kost, K. J., Sammon, M. C., \& Viratyosin, T. (2020). The unprecedented stock market impact of COVID- 
19 (No. w26945). National Bureau of Economic Research.

[2] Lee, H. S. (2020). Exploring the initial impact of COVID-19 sentiment on US stock market using big data. Sustainability, 12(16), 6648.

[3] Mazur, M., Dang, M., \& Vega, M. (2021). COVID19 and the march 2020 stock market crash. Evidence from S\&P1500. Finance Research Letters, 38, 101690.

[4] Ozili, P., \& Arun, T. (2020). Spillover of COVID19: Impact on the Global Economy. Research Papers in Economics.

[5] Zaremba, A., Kizys, R., Aharon, D. Y., \& Demir, E. (2020). Infected Markets: Novel Coronavirus, Government Interventions, and Stock Return Volatility around the Globe. Finance Research Letters, 35, 101597.

[6] He, Q., Liu, J., Wang, S., \& Yu, J. (2020). The impact of COVID-19 on stock markets. Economic and Political Studies, 8(3), 275-288.

[7] Liu (2020), China's Economy under COVID-19: Short-Term Shocks and Long-Term Changes. Formulas and tables. its short-term, medium- and long-term impact on China's economy cannot be ignored.

[8] Chen (2020), Development Prospect of China's New Consumer Economy in the New SituationConcurrently Discussing the Impact of COVID-19. experimental method. In the short term, the impact of the epi- demic on the economy is mainly concentrated in industries such as catering, tourism and transportation.

[9] Garg, K. D., Gupta, M., \& Kumar, M. (2021). The Impact of COVID-19 Epidemic on Indian Economy Unleashed By Machine Learning. In IOP Conference Series: Materials Science and Engineering (Vol. 1022, No. 1, p. 012085). IOP Publishing.

[10] Thorbecke, W. (2020). The impact of the COVID19 pandemic on the u.s. economy: evidence from the stock market. Discussion papers.

[11] Sulistiowati, D., Syahrul, M. S. , \& Rianjaya, I. D. . (2021). Risk analysis of gold sale price and investment of antam shares using expected shortfall in pandemic COVID-19. Jurnal Matematika Statistika dan Komputasi, 17(3), 428-437.

[12] Gao, X. , Ren, Y. , \& Umar, M. (2021). To what extent does COVID-19 drive stock market volatility? a comparison between the u.s. and china. Ekonomska Istraživanja / Economic Research, 1-21. 